\title{
Plumbing the depths of dental decay
}

\author{
The finding that maternal lead ingestion increases the prevalence of caries in rat pups may explain \\ the greater incidence of tooth decay among inner city children (pages 1024-1025).
}

$\Gamma_{\text {batt }}^{\text {Rom }}$ OM WATER PIPES to paints, varnishes and batteries, and as an additive in gasoline (petrol), lead has found a host of different applications. However, its most publicized and notorious role is as a major inner city environmental pollutant. It is surprising that lead, identified as a health risk more than 50 years ago, is still a major problem among low-income inhabitants of inner cities.

There is considerable evidence that children living in old, decayed nineteenth century housing are very much at risk of mental impairment and other illnesses resulting from the intake of lead-contaminated water flowing through lead piping and, more importantly, from the ingestion of flakes of lead-based housepaint. A study by Needleman and colleagues ${ }^{1}$ two decades ago showed that the IQ scores of inner city children exposed to subclinical lead burdens were four points lower than those of children never exposed to lead. Furthermore, subsequent investigations found that children from the same inner-city areas also had a higher prevalence of dental caries ${ }^{2}$. But, there are conflicting reports in the literature regarding the influence of lead on susceptibility to dental caries ${ }^{3}$.

Watson et al. ${ }^{4}$ report on page 1024 of this issue that rat pups born to mothers exposed to lead ( $34 \mathrm{ppm}$ in drinking water) during adulthood, pregnancy and lactation have a $40 \%$ increase in dental caries (see figure) and a $30 \%$ decrease in stimulated parotid gland function. The lead levels in milk of exposed mothers were ten-fold greater than levels in blood, suggesting that lead is concentrated in mammary gland tissue. These findings are important because they reveal two hitherto unrealized aspects of lead toxicity. First, it appears that maternal ingestion of lead results in transfer to offspring, most probably through breast milk. Second, the prevalence of dental caries in children may be directly related to maternal exposure to lead, and this effect may be mediated by a reduction in the flow of saliva from the parotid glands.

\section{Martin E. J. Curzon \& K. JACK TOUMBA}

Until this report, it had been presumed that lead would exert its detrimental effect on teeth through its
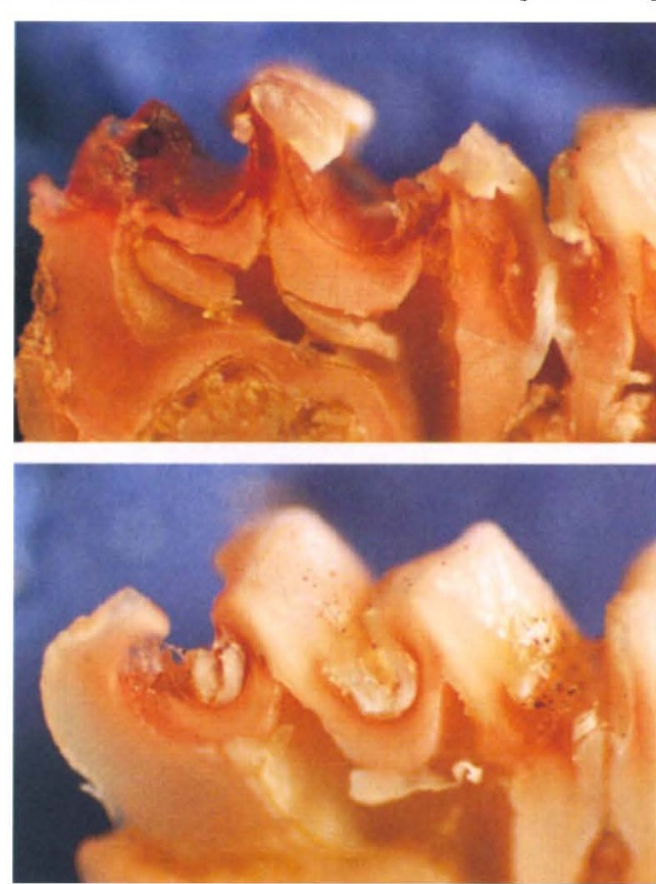

Dental caries in rat pups born to (top) lead-exposed or (bottom) control mothers. Views are of mandibular first molars sliced down the midline and clearly show severe sulcal decay (carious lesions associated with grooves on teeth) in the lead-exposed pups.

inclusion in tooth enamel, engendering a defective enamel hydroxyapatite that is more susceptible to dissolution in acids produced by plaque bacteria. No doubt this presumption was based upon the knowledge that the beneficial effects of fluoride result from its incorporation into enamel apatite, rendering the tooth more resistant to demineralization and decay. Watson and colleagues suggest another mechanism by which pre- and perinatal lead exposure may contribute to dental caries. They show that lead interferes with the normal development of the parotid glands, resulting in impaired function and a reduction in salivary flow. Saliva is an oral solution that not only aids in digestion of food but also has bactericidal proper- ties and contains ions that buffer against plaque acids. It would have been useful if the authors had measured the concentration of lead in the teeth of pups born to exposed mothers as this would have helped to clarify the role of parotid gland dysfunction in the formation of caries. The fact that lead may have detrimental effects on the development of other glands and organs in the body should also be considered.

One must always be cautious when extrapolating animal studies to humans. Caries is a multifactorial disease and there are probably many other factors apart from lead that contribute to the formation of cavities. However, the finding that preand perinatal exposure of rats to lead results in a dramatic increase in dental caries should prompt further studies among inner-city children. Although most cities have fluoridated water, the rates of dental caries among inner-city children remain remarkably high. The Watson study suggests that lead is the culprit - a culprit that can easily be dealt with by removing the vestiges of lead pipes and lead-based housepaint from older homes.

It has been postulated that the Roman Empire eventually collapsed because of a decline in intelligence caused by drinking water contaminated by lead. Perhaps, however, the true reason was the chronic toothache that afflicted the Roman legions rendering them incapable of defending the Empire.

1. Needleman, H.L. et al. Deficits in psychological and classroom performance of children with elevated dentine lead leveis. N. Engl. J. Med. 300, 689-695 (1979).

2. Stack, M.V. Lead. In Trace elements and dental disease. (eds. Curzon, M.E.J. \& Cutress, T.W.) pages 357-385 (John Wright-PSG Inc., Boston, 1983).

3. Curzon, M.E.J. \& Crocker, D.C. Relationships of trace elements in human tooth enamel to dental caries. Arch. Oral Biol. 23, 647-653 (1978).

4. Watson, G.E., Davis, B.A., Raubertas, R.F., Pearson, S.K. \& Bowen, W.H. Influence of maternal lead ingestion on caries in rat pups. Nature Med. 3, 1024-1025 (1997).

University of Leeds School of Dentistry

Leeds LS2 9LU, UK 